\title{
EM PROCESSO: IMAGENS E MEMÓRIAS COMO MATERIAIS DE CRIAÇÃO NO CONTEXTO DO DRAMA
}

\author{
Wagner Monthero ${ }^{1}$
}

Este artigo relata e analisa um experimento onde o recurso de imagens visuais é utilizado como matriz para os processos de criação em Drama/Teatro. O objetivo foi investigar a interação imagem-memória no contexto do drama. Os procedimentos incluíram observação, materialização e seleção de imagens como base para criação de ações. As ações foram inseridas no contexto do Drama através da utilização do texto como pré-texto e do estímulo composto. Os resultados alcançados permitiram problematizar os processos de subjetivação quando confrontados com a criação coletiva dentro de um contexto ficcional.

Palavras-chave: atuação, materiais, drama, contexto de ficção, estímulo composto.

Abstract

This article describes and analyses an experiment where images are used as stimulus to develop creation processes in

Drama/Theatre. The aim was investigating the interaction

between image and memory within the drama context.

The procedures included observation, materialization and selection of images as starting point for the creation of actions. The actions were inserted in the drama context through the text as pre-text and the compounding

stimulus. Through the archieved outcomes it is possible to problematize the confront between subjective processes and collective creation within a ficitonal context.

Keywords: action, materials, drama, context of fiction, compounding stimulus. 


\section{As provocações da memória nos processos de criação}

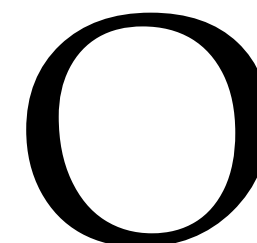

espaço para a realização das primeiras sessões deste experimento ${ }^{2}$ foi preparado com o objetivo de estimular o imaginário e a capacidade perceptiva dos participantes. Quatro grandes varais contendo um conjunto aproximado de 100 imagens visuais extraídas de revistas diversas delimitaram o espaço de trabalho. Estas imagens de caráter variado (pessoas, gestos, paisagens, objetos) foram utilizadas como ponto de partida para os processos de criação.

A dinâmica de relação dos atoresparticipantes com as imagens iniciou-se com a observação das mesmas. Após um primeiro contato com as imagens através da observação, os atores foram instruídos a materializá-las no corpo, percebendo corporalmente este estímulo e transformando cada imagem observada em uma forma. Da etapa de materialização passou-se à etapa de seleção: a partir de todas as formas materializadas cada ator selecionou 10 delas para compor uma sequência.

A teoria de Henri Bergson é aqui introduzida, pois me permite o entendimento do papel da percepção e da memória nos processos de criação.

Segundo o filósofo, as lembranças da memória são ativadas no momento da percepção. "Por mais breve que se suponha uma percepção, com efeito, ela ocupa sempre uma certa duração e exige consequentemente um esforço da memória" (BERGSON, 2010, p. 31). Desta forma, os dados fornecidos pelos sentidos são misturados aos detalhes das lembranças, que arquivadas na memória vêm à tona.

1 Wagner Monthero é ator, reingressou na Universidade em 2009 no curso de Teatro da UDESC e atualmente cursa mestrado na mesma instituição, onde pesquisa atuação em Drama.

2 Este experimento foi realizado no Departamento Artístico Cultural (DAC) da UFSC, através do projeto Experimentos Cênicos em Teatro vigente nesta instituição, totalizando $20 \mathrm{~h}$ de trabalho, com 15 participantes. Drama, Process Drama ou Drama Education é uma atividade teatral caracterizada pela construção coletiva de uma narrativa dramática em cena.
A memória constitui assim, a principal contribuição da consciência individual na percepção, determinando o recorte de nosso olhar sobre o mundo à nossa volta.

No âmbito desta prática, as imagens visuais funcionaram como intimações ${ }^{3}$ do imaginário e foram materializadas por meio de formas. Nesta etapa do trabalho a emergência das singularidades pôde ser observada pela diversidade de formas criadas a partir de uma mesma imagem. No trânsito entre imagem e imaginário, a imagem que se configura como um signo provoca as memórias de cada ator e através da materialização é transformada em símbolo. Nesta forma resultante estão implicadas as subjetividades.

Para Bergson, os dados fornecidos pelos sentidos funcionam como signos destinados a evocar antigas lembranças, e como tal, podem inclusive deslocar a realidade da percepção. Isto implica que não existe uma percepção ideal, nem impessoal, ela é sempre influenciada por estes "acidentes individuais" do passado, conforme sugere o autor.

Neste sentido, o fato de uma mesma imagem ganhar formas e contornos diferenciados poderia exemplificar como estes acidentes individuais do passado definem as qualidades subjetivas acrescentadas a esta imagem.

\section{Percepção-Memória-Ação}

Se as reflexões sobre percepção e memória me permitem relatar as primeiras sessões deste experimento, recorro agora ao conceito de materiais proposto por Matteo Bonfitto para focalizar os processos de atuação e a construção de ações físicas. Cada ator elaborou uma sequência própria de imagens. Esta estrutura de formas em potência foi explorada neste processo de construção de ações e no decorrer das etapas seguintes.

3 Por intimações entende-se aquilo que nos impulsiona à ação ou à inércia em relação ao meio no qual estamos inseridos e do qual participamos voluntária ou involuntariamente (DURAND apud OLIVEIRA, 2011, p. 14). 
Para Bonfitto, materiais são elementos de diferentes naturezas que constituem matrizes geradoras para o trabalho do ator. Ao apropriar-se do conceito aristotélico de "matéria enquanto potência operativa e criativa", este autor nivela os materiais em três categorias:

O corpo, entendido como unidade psicofísica, pode ser definido como material primário, pois é nele que os materiais secundários e terciários estão contidos, e será sobre ele que tais materiais atuarão; a ação física será o material secundário, pois além de conter os materiais terciários, ela é, como veremos, o elemento estruturante dos procedimentos expressivos do corpo; o ritmo e o aspecto ético são aqui classificados entre os materiais terciários, pois são procedimentos e/ou elementos constitutivos da ação física, atuando em seus processos de preenchimento e justificação (BONFITTO, 2006b, p. 20).

A estrutura, enquanto material, norteou um processo de buscas e descobertas quanto às possibilidades de execução de ações. As formas funcionaram como ponto de partida e referência neste trabalho. Os atores-participantes foram instruídos a pesquisar diferentes ações a partir de uma mesma forma, explorando sua capacidade para catalisar processos psicofísicos.

Neste jogo de manipulação das formas em busca de ações, o ator está sujeito à estímulos simultâneos que surgem durante o processo e que podem ser úteis na estruturação de sua composição. No entanto, considero que estes estímulos (extras) podem desviar o ator do foco na forma, causando o esvaziamento da mesma. A forma é pensada como uma maneira de provocar o imaginário e a estimulação das memórias quanto ao desenvolvimento de ações.

Neste sentido, a etapa de materialização das imagens através de formas consistiu de um registro corporal. Este registro, impregnado de sensações perceptivas possui o potencial de estimular sensivelmente as memórias e estando impresso como uma marca pode ser acessada a qualquer momento, em busca de organicidade e energia para a construção das ações e das cenas.
Estes princípios foram desenvolvidos por Grotowski na preparação do ator e estruturaçãodeações, visandocompreender o corpo como memória: “as memórias se mostram e se organizam de uma forma orgânica em todas as ações dos atores; um espetáculo é um intenso jogo do ator com suas próprias memórias, o corpo não tem memória, ele é memória" (GROTOWSKI apud LIMA, 2009).

Considero que este trabalho de materializar imagens e pesquisar ações parte do encontro de cada ator com algo que está ausente - a imagem representada - que o impulsiona a dar sentido àquilo que ele vê e o estimula. As imagens que representam algo, um homem sobre um cavalo com uma arma apontada, ou de uma moça lendo um livro ou de uma parreira de uvas ou de um par de luvas envolto por um colar, ao se configurarem como a ausência destas pessoas, lugares e objetos consistem também em sua substituição. A imagem enquanto ausência daquilo que ela representa é, portanto, uma enganação que ocorre com uma coisa que não está ali (RANCIÈRE, 2010, p. 92). ${ }^{4}$ A imagem, assim, não é aquilo que o ator vê, mas o sentido que ele lhe atribui, pois a imagem objetivamente não revela nada e pode ser lida de diversas maneiras.

No âmbito do experimento, coube a cada ator-participante no trabalho com as imagens e as formas, permitirse a uma trajetória de busca de sentidos a ser atribuída ao estímulo, trajetória esta guiada pelo fenômeno perceptivo e pela estimulação sensível das memórias. A interação entre estímulo e processo criativo está estreitamente relacionada com as matrizes imaginativas da história e cultura de cada um. Esta relação com o material não se dá apenas através de técnicas e conteúdos a serem aprendidos, mas também a todo um comportamento que perpassa questões filosóficas ideológicas, pessoais e culturais.

4Em Trabalho sobre a imagem, Jacques Rancière faz reflexões a partir do trabalho da artista Esther Shalev-Gerz realizado sobre a memória dos campos de concentração. 
Na prática relatada, o trabalho com a pesquisa de ações demorou-se por algumas sessões. Dentro de uma perspectiva de descobrir possibilidades, as ações foram testadas quanto ao deslocamento de sentidos e atribuição de novos sentidos objetivando a construção de uma partitura. Para tal, os atores escolheram uma única ação dentre as várias testadas sobre cada forma. Neste sentido, a partitura final pode ser considerada como a tradução das subjetividades de cada ator.

Aberto à potência das descobertas e dos achados, cada ator estrutura sua composição pautada no trabalho sobre si mesmo. O estímulo é o meio através do qual o ator pode lançar-se sobre si em busca do oculto, em busca de tocar uma qualidade de memória que amplia a percepção de si mesmo. As sensações encontradas são reelaboradas, re-significadas e re-apropriadas através da ação.

\section{No contexto do drama}

O Drama, considerado como um meio de investigação cênica tem como finalidade a construção de uma narrativa teatral em grupo. A elaboração desta narrativa ocorre de forma processual através da efetiva participação de todos os integrantes, caracterizando-se como uma forma de arte coletiva.

O trabalho desenvolvido até então, consistiu na investigação de procedimentos de atuação centrados na autonomia expressiva do ator e na interação de suas memórias com imagens visuais. Os processos de criação foram expandidos no contexto do Drama, uma vez que este possui o potencial de instauração de um ambiente propício ao desenvolvimento dos processos perceptivos de cada participante.

Neste sentido, foram focalizados o prétexto no contexto da ficção e a utilização do estímulo composto.

Um processo de drama normalmente se inicia com a escolha do pré-texto e a instauração de um contexto de ficção. $\mathrm{O}$ pré-texto, que pode ser literário (extraído de um texto dramático ou não-dramático), imagético ou áudio-visual funciona como um roteiro, ou um pano de fundo para delimitar o desenvolvimento do processo e orientar as opções do coordenador. Caracterizado como ponto de partida, guia a seleção e a identificação das atividades e situações a serem exploradas cenicamente: “O pré-texto opera em diferentes momentos como uma espécie de 'forma-suporte' para os demais significados a serem explorados e como tal define a natureza e os limites do contexto dramático" (O’NEILL apud CABRAL, 2006, p. 15).

A introdução do contexto pelo coordenador é a instauração de uma atmosfera que permita o engajamento emocional e intelectual dos participantes no processo e na história a ser desenvolvida. O contexto de ficção está relacionado com a criação de expectativas e o estabelecimento de tensões que desafiam a participação dos integrantes do grupo.

No experimento em questão, o contexto de ficção e a utilização do texto como pré-texto permitiu o desenvolvimento dos processos de subjetivação iniciados na interação imagem-memória através da apropriação do contexto e do texto pelos sujeitos.

Através do contexto proposto os atores-participantes interagiram em grupos. Este momento de encontro e confronto de individualidades através da criação de cenas permitiu a resignificação das ações inclusive em relação aos fragmentos de textos.

O texto escolhido, Nós e Eles, de David Campton, ${ }^{5}$ narra a história de dois grupos distintos de pessoas que chegam a um lugar e passam a conviver neste mesmo espaço. A convivência entre os grupos traz a imediata necessidade de divisão do espaço que leva a uma série de conflitos. Algumas questões abordadas para o teatro, cinema e rádio e foi considerado um dos primeiros dramaturgos britânicos a escrever no estilo Teatro do Absurdo (VIDOR, 2010, p. 50). 
por este texto foram exploradas como a convivência entre grupos distintos, a mudança de vida e as expectativas geradas com esta mudança. ${ }^{6}$

Este trabalho foi realizado em um local adequado à exploração de questões como divisão do espaço e confronto entre grupos sugeridas pelo pré-texto, a Igrejinha da UFSC. ${ }^{7}$ Durante o trabalho em uma das sessões, valendo-me da estratégia do teacher-in-role ${ }^{8}$ entrei em cena e fechando todas as portas do local desafiei os participantes: “A partir deste momento, todos vocês estão trancados neste lugar, por tempo indeterminado. Vocês não sabem o real motivo deste confinamento e devem se dividir em grupos com pessoas que vocês não conhecem. Cada grupo deve escolher seu espaço e permanecer nele com o objetivo de melhor conviverem entre si."

Assim, a questão de convivência entre grupos, abordada no texto de Campton foi explorada em relação a questões de identidade e diferenças. As experiências de cadaintérpretetrabalhadasatéentãoatravés das imagens e ações foram evidenciadas pelo contexto de ficção. A partitura foi resignificada dentro de um contexto e através da interação entre os atores nos grupos, funcionando como ponto de partida para o estabelecimento das diferenças. Isto foi reforçado pelos fragmentos textuais.

60 utras questões do texto com potencial de serem abordadas são apontadas por CABRAL em $O$ professor-diretor e a busca da teatralidade em contextos periféricos (2004) tais como: limites entre o público e o privado, processo de acomodação e confronto entre recém-chegados a um mesmo lugar, ocupação da terra.

7 A Igrejinha da UFSC, que juntamente com o Teatro da UFSC e a Casa do Divino integram o prédio do Departamento Artístico Cultural da Universidade Federal, é um local para realização de oficinas, cursos de arte e apresentações artísticas. Este prédio antigo possui uma variedade de espaços que foram "habitados" pelos diferentes grupos: coro, escadas, plataformas com degraus, cúpula central etc.

8 Teacher-in-role que literalmente significa professor no papel é uma estratégia muito utilizada em drama onde o condutor do processo assume papéis e/ou personagens com o objetivo de interagir com os participantes. Este termo foi traduzido por CABRAL (2006) como professor-personagem. Para maiores informações, ver em CABRAL (2006, p. 19-20) e $\operatorname{VIDOR}(2010$, p. 43-94)
A noção de identidade na esfera deste trabalho é vista como processos de identificação por parte dos atores com os materiais disponíveis onde a mobilidade está presente em todo o percurso. O trabalho do ator desenvolvido através do intercurso de suas memórias individuais com estes materiais se caracteriza como processos de individuação, através dos quais o indivíduo pode ampliar as próprias referências intelectuais e afetivas (BONFITTO, 2009, p. 25).

As diferenças e as singularidades colocam-se como peça-chave no desenvolvimento dos processos de drama. A construção coletiva de uma narrativa ocorre a partir de negociações: a) entre as relações individuais com o contexto e outros elementos; b) entre as relações individuais com o grupo; c) nas relações entre os diferentes grupos. A dinâmica destas relações reforça as diferenças.

Após o trabalho com o contexto de ficção e com o texto como pré-texto, introduzi o estímulo composto. O estímulo composto é um recurso que em Drama envolve o participante com o contexto dramático e com a narrativa a ser construída, incentivando a fazer investigações paralelas, esboçando hipóteses e ideias. As caixas de estímulos são constituídas de objetos, que ao serem explorados, originam dados através dos quais cada integrante contribui com a narrativa a ser desenvolvida. Deste modo, a introdução do estímulo composto gera expectativas e estimula as habilidades dramatúrgicas.

A estimulação de habilidades dramatúrgicas baseia-se na ideia defendida por John Somers de que a criação de narrativas é um aspecto indispensável da experiência humana. Para este autor, o ato de criar histórias nos permite "organizar momentaneamente a experiência em uma série de memórias, prever um futuro e experienciar através da história dos outros aspectos do mundo que não experienciamos nós próprios" (SOMERS, 2008) 9 .

9 Este artigo foi traduzido por Biange Cabral e esta sendo publicado neste número. 
As caixas de estímulo composto consistem de um recipiente apropriado que contêm diferentes artefatos: objetos de uso pessoal, fotografias, cartas e outros documentos, imagens, ferramentas, itens de vestuário, fragmentos de texto etc. A variedade do conjunto permite que diferentes histórias possam emergir através da significância atribuída pelos integrantes aos diferentes objetos e a partir da criação de conexões e especulações a serem articuladas com a história em desenvolvimento.

Na prática que aqui relato, o estímulo composto foi introduzido para ampliar as criações individuais a partir da partitura de ações e fornecer elementos que contribuam para o desenvolvimento das narrativas individuais e em grupo. Quatro caixas foram utilizadas e cada qual continha cerca de sete elementos, entre:

- fragmentos de texto (dispostos em pequenos envelopes ou escritos em papéis envelhecidos)

- objetos pessoais (arranjo de cabelo, relógio de bolso antigo, rosário, colar, moedas antigas, gema, ticket de metrô etc.)

- imagens diversas (grupo de pessoas, um homem ao lado de um crânio, a imagem de um homem formada por vegetais, mapa etc)

- outros(pequenorecipientecontendo unhas e outro com cabelos cortados, bula do medicamento Frontal, chave antiga, envelope com folhas secas coladas em um papel etc.)

Estes objetos remetem a espaços e atmosferas diferentes. Os atoresparticipantes foram instruídos a fazer o cruzamento entre os objetos e os segmentos de sua partitura de ações. Desta forma, os objetos do estímulo composto também utilizados como materiais foram apropriados em conexão com as ações, recriando e reorganizando as partituras em diferentes direções.

Esta etapa foi realizada através de experimentação prática. Cada atorparticipante precisou identificar os materiais mais adequados na execução de suas ações: é um trabalho subjetivo de relação do ator com o objeto que o estimula e como o estimula, que essencialmente não pode ser provocado por conteúdos pré-estabelecidos. Estes processos são caracterizados pela conexão entre as dimensões interior e exterior do ator, gerando partituras que contêm materiais caracterizados por diferentes graus de abstração e subjetividade (BONFITTO, 2006a, p. 49).

No âmbito desta prática propus um deslocamento quanto à utilização do estímulo composto. Em Drama os pacotes de estímulo são introduzidos com o objetivo de oferecer elementos que contribuam com a construção da narrativa. Desta forma, o estimulo está vinculado à construção dramatúrgica através da criação de hipóteses e postulações sobre o material em relação ao contexto.

Contudo, o estímulo composto foi explorado também como um material de criação com o objetivo de ampliar a partitura de ações e o discurso cênico dos atores. No entanto, mesmo não havendo interesse de construção de uma narrativa coletiva, narrativas individuais e em grupo foram criadas durante a exploração deste material. Isso ocorreu devido às circunstâncias através das quais o estímulo composto foi introduzido: dentro de um contexto de ficção e de acordo com as situações a serem investigadas com o processo.

\section{Considerações Finais}

Este trabalho se desenvolveu através de um percurso de exploração sensorial e permitiu a interação entre o real (corpo, imagens, espaço, objetos) e o virtual (imaginário, experiências pessoais, percepção). A influência da memória nesta interação determinou a construção de discursos cênicos centrados em singularidades e diferenças.

As singularidades foram evidenciadas pelo contexto de ficção criado a partir do texto Nós e Eles e o contexto de ficção inseriu um contexto coletivo que 
permitiu as relações entre as subjetividades estabelecidas.

Em relação aos processos de subjetivação, constatei que alguns atoresparticipantes apresentaram dificuldades em articular suas ações ao contexto. O fato de o contexto ter sido introduzido com o estabelecimento de uma situaçãoproblema, gerando expectativas através da tensão dramática, pode ter dificultado a identificação de ações da partitura a ser utilizada naquele momento. No entanto, outros conseguiram ampliar e re-significar a partitura através do seu cruzamento com o contexto e com o estímulo composto.

Através da identificação destas facilidades e dificuldades pontuo os seguintes questionamentos: A autonomia dada aos atores-participantes durante todo o processo de criação comprometeu a articulação de ações ao contexto? A articulação de ações requer do atorparticipante habilidade para se relacionar com diferentes materiais de criação?

Pensar que neste experimento o trabalho do ator foi observado como processos de composição em interação com estímulos diversos permite outro questionamento: A necessidade de resignificar ações e adequá-las a um contexto poderiam estar relacionadas à apropriação dos materiais disponíveis através dos referenciais de memória?

Esta prática possibilitou a identificação e exploração de camadas de materiais no processo de criação. O conjunto de imagens foi o primeiro material. Com a introdução do contexto, a partitura criada a partir das imagens funcionou como outro material. As partituras revelam os processos de subjetivação de cada participante, que dentro de um contexto interage com outros materiais encontrados: o texto como prétexto e as caixas de estímulo.

Os materiais são estímulos para a criação que possuem o potencial de ativar o arquivo de memórias de cada ator, que através do trabalho sobre si mesmo, constrói gradativamente um discurso cênico baseado na experienciação e na reinvenção de sua realidade.

\section{Referências bibliográficas}

BERGSON, H. Matéria e Memória: Ensaio sobre a relação do corpo com o espírito. São Paulo: Editora Martins Fontes, 2010.

BONFITTO, M. Do Texto ao Contexto. In: Revista Humanidades: Teatro Pós-Dramático, n. 52 (Edição Especial), pp. 45-52. Brasília: Editora Unb, 2006a.

O Ator-Compositor. São Paulo:

Editora Perspectiva, 2006b.

Os Seres Ficcionais: Identidade

e Alteridade - Exploração-DissecaçãoInvenção de materiais de atuação. In: Urdimento Revista de Estudo em Artes Cênicas da Universidade do Estado de Santa Catarina, v. 1, n. 12, p. 21-28. Florianópolis, mar. 2009.

CABRAL, B. A. V. O diferente em cena: Integração ou Interação. In: Ponto de Vista Revista de Educação e Processos Inclusivos, n. 06. Florianópolis: UFSC, Centro de Ciências da Educação, NUP/CED, 2004.

Drama como Método de Ensino. São

Paulo: Editora Hucitec, 2006.

A Estética do dissenso em processos coletivos. In: CAVAS, N.; ISAACSSON, M.; FERNANDES, S. (org.). Ensaios em cena. Salvador, BA: ABRACE; Brasília, DF: CNPq, 2010.

LEONARDELLI, P. A memória como recriação do vivido aplicada às artes performativas. In: Sala Preta Revista de Artes Cênicas, n. 09, pp. 191-201. São Paulo: ECA-USP, 2009. LIMA, T. M. Experimentar a memória ou experimentar-senamemória:apontamentos sobre a noção de memória no percurso artístico de Jerzy Grotowski. In: Sala Preta Revista de Artes Cênicas, n. 09, pp. 159-169. São Paulo: ECA-USP, 2009.

RANCIÈRE, J. Trabalho sobre a Imagem. In: Urdimento Revista de Estudo em Artes Cênicas da Universidade do Estado de Santa Catarina, v. 1, n. 15, p. 91-105. Florianópolis, out. 2010. SOMERS, J. Narrative, Drama and Compound Stimulus. Tradução de Biange Cabral. In: Education $\mathcal{E}$ Theatre Journal, n. 09, Tradução de Biange Cabral. Atenas, GR.

VIDOR, H. B. Drama e Teatralidade: O ensino do teatro na escola. Porto Alegre: Editora Mediação, 2010. 